\title{
Da Indiferença ao Engajamento: a participação da China em operações de paz das Nações Unidas ${ }^{1}$
}

\author{
From Indifference to Engagement: \\ China's participation in United Nations \\ peace operations
}

DOI: $10.21530 /$ ci.v13n1.2018.724

Renan Holanda Montenegro²

\section{Resumo}

A China ingressa na Organização das Nações Unidas (ONU) em 1971, mas mantém uma postura de distanciamento e desconfiança praticamente durante toda primeira década como membro oficial. Hoje, os chineses estão entre os principais contribuidores de pessoal para as operações de paz, enviando desde equipes de apoio a batalhões de infantaria, sendo o membro mais ativo nesse sentido entre aqueles com assento permanente no Conselho de Segurança. O que explica tal mudança de comportamento? Quais fatores determinam a participação da China em missões de paz? O objetivo central do presente artigo é apresentar um panorama da literatura sobre o assunto, tendo em conta a variada gama de fatores causais identificados e a possibilidade de agrupá-los em categorias explicativas mais amplas. A metodologia utilizada ainda lança mão de ferramentas de estatística descritiva. Com esse empreendimento, espera-se prestar uma contribuição para os estudos sobre política externa chinesa em geral, com foco específico nas relações China-ONU e no engajamento de Pequim nas operações de paz.

Palavras-chave: China; Organização das Nações Unidas; Operações de Paz; Teoria das Relações Internacionais.

1 Versões preliminares deste trabalho foram apresentadas no 9 Congresso Latino-Americano de Ciência Política, em Montevidéu, e no 1 Seminário Nordestino de Estudos da Ásia, no Recife.

2 Doutorando em Ciência Política (UFPE), Pesquisador Associado do Instituto de Estudos da Ásia (UFPE) e professor da Universidade Federal de Sergipe (UFS). Mestre em Relações Internacionais (UERJ).

Contato: renanholanda@bol.com.br.

Artigo submetido em 29/11/2017 e aprovado em 12/03/2018. 


\begin{abstract}
China joins the United Nations (UN) in 1971, but maintains a position of detachment and mistrust throughout the first decade as an official member. Nowadays, the Chinese are among the major contributors of personnel for peace operations, ranging from support equipment to infantry battalions, being the most active member in that sense among those

with permanent seat on the Security Council. What explains this behavioral change? What factors determine China's participation in these missions? The main objective of this paper is to present an overview of the literature on the subject, taking into account the wide range of causal factors identified and the possibility of grouping it in broader explanatory categories. The methodology also applies descriptive statistics tools. With this enterprise, the article intends to contribute to the studies on Chinese foreign policy in general, with a specific focus on China-UN relations and on engagement of Beijing in peace operations.
\end{abstract}

Keywords: China; United Nations; Peace Operations; International Relations Theory.

\title{
Introdução
}

Membro oficial da Organização das Nações Unidas (ONU) desde 1971, a República Popular da China inicialmente demonstrou um comportamento com relação à instituição pautado pelo distanciamento e até pela desconfiança, mesmo tendo algum poder de ingerência como membro permanente do Conselho de Segurança. Entretanto, tal postura se alterou radicalmente com o passar do tempo. Nesse artigo, analisa-se essa inflexão comportamental com base na atuação chinesa nas operações de paz (peacekeeping operations).

Na primeira década integrando oficialmente a ONU, os chineses tiveram uma postura tanto de indiferença quanto de oposição à criação e continuação dessas operações. Somente nos anos de 1980 é que o país começa a demonstrar uma atitude de maior suporte, seja pagando sua contribuição anual ou votando a favor de algumas resoluções. A primeira contribuição do país para essas missões, ainda que tímida, só veio a acontecer em 1990.

Desde então, o envio de pessoal tem crescido e se diversificado, indo desde observadores e equipes de apoio até batalhões de infantaria. Mais recentemente, o presidente Xi Jinping anunciou a doação de US\$ 1 bilhão para o fundo de paz e desenvolvimento das Nações Unidas e a criação de uma força permanente de 8 mil homens para as missões de paz. Em 2016, a capital Pequim sediou o primeiro curso de capacitação voltado para soldados que atuam em missões de paz, uma iniciativa feita através de parceria entre o governo chinês e a ONU. 
Essa nova postura diante do multilateralismo onusiano também fez com que a China se transformasse no segundo maior financiador das referidas operações, a contribuir com $10 \%$ do orçamento total até 2018, atrás apenas dos Estados Unidos (NEW YORK TIMES, 2015; DIÁRIO DO POVO ONLINE, 2016; CRI, 2016). Dada essa clara mudança de postura da China quanto ao sistema ONU em geral, e aos arranjos multilaterais de segurança em particular, cabe a pergunta que dá partida ao presente trabalho: quais fatores explicam a participação da China nas operações de paz das Nações Unidas?

De acordo com Shambaugh (2013), a contribuição da China nas operações de paz da ONU constitui o que talvez seja o traço mais notável do engajamento do país em termos de segurança internacional. Apesar disso, em geral, a maior parte dos trabalhos realizados sobre o tema consiste em narrativas de cunho histórico que se limitam a examinar a evolução da participação chinesa como um peacekeeping state.

No presente artigo, o objetivo central é promover um levantamento dos principais fatores trabalhados pela literatura como relevantes para compreender a participação chinesa nas operações de paz, levando em conta, sobretudo, a variedade das causalidades identificadas e, adicionalmente, a possibilidade de agrupá-las em categorias explicativas mais amplas. A metodologia utilizada também lança mão de técnicas de estatística descritiva, que buscam ilustrar a evolução do envolvimento chinês nas missões de paz, bem como os países e regiões que mais receberam soldados chineses.

Além da presente introdução, o texto ainda conta com outras três seções, excetuando a conclusão. Na próxima, destaca-se brevemente a evolução da participação chinesa nas missões de paz em perspectiva histórica. Em seguida, apresentamos dados quantitativos a respeito do assunto - o intervalo de análise se situa entre 1990 e 2015. Depois, são apresentadas as principais contribuições sobre o tema trazidas pela literatura. Nessa etapa, avalia-se de que forma a literatura incorpora aspectos explicativos complementares e/ou contraditórios. Por fim, são tecidas algumas considerações conclusivas.

\section{Breve histórico da participação chinesa nas operações de paz}

Ao término de 2015, a China contribuía com um pessoal de 3.045 para dez das 18 operações de paz da ONU em andamento. Com isso, o país é o membro permanente do Conselho de Segurança que mais envia contribuições, posição 
que ocupa desde março de 2004. No quadro geral de países, a China aparecia em $9^{\circ}$ lugar, sendo - ao lado da Índia, $3^{\circ}$ lugar - a única potência entre os principais contribuintes, figurando junto a Estados como Bangladesh (10), Etiópia (20), Paquistão (4) e Ruanda (5³) .

Quadro 1. Participação da China em operações de paz da ONU (dez/2015)

\begin{tabular}{|c|c|c|}
\hline Missão & Local & Contribuição \\
\hline MINURSO & Saara Ocidental / África & 10 \\
MINUSMA & Mali / África & 402 \\
MONUSCO & Rep. Dem. do Congo / África & 232 \\
UNAMID & Darfur / África & 235 \\
UNFICYP & Chipre / Europa & 3 \\
UNIFIL & Líbano / Ásia & 418 \\
UNMIL & Libéria / África & 667 \\
UNMISS & Sudão do Sul / África & 1.068 \\
UNOCI & Costa do Marfim / África & 6 \\
UNTSO & Oriente Médio / Ásia & 4 \\
\hline
\end{tabular}

Fonte: Elaboração própria com base em dados da ONU (peacekeeping.un.org).

Historicamente, o envolvimento da China nas referidas operações é dividido em fases pela literatura especializada (FRAVEL, 1996; HE, 2007; FUNG, 2015). Na primeira fase, que engloba os primeiros dez anos dentro do sistema ONU, a diplomacia de Pequim se opôs à criação e à continuação de todas as operações no período: três no total, todas referentes ao conflito árabe-israelense.

A discordância chinesa se expressou em três frentes: 1) não participação nas votações do Conselho de Segurança; 2) não pagamento das contribuições financeiras anuais às missões; e 3) não enviando tropas para as operações em andamento. Em termos gerais, a visão da China era de que as operações de paz representavam uma faceta do jogo protagonizado pelas grandes potências da época, constituindo apenas um pretexto para a intervenção dos Estados Unidos ou da União Soviética em assuntos de pequenos Estados.

3 Em 2016, o status da contribuição chinesa caiu consideravelmente, chegando a 2.630. Entretanto, esse decrescimento não será discutido aqui, haja vista que o intervalo temporal da presente análise se situa, como já mencionado anteriormente, entre 1990 e 2015. Dados disponíveis no portal peacekeeping.un.org. 
A bem da verdade, nesse período a China demonstrava desconfiança, quando não repulsa, aos mais diversos tipos de organizações internacionais, fossem elas regionais ou multilaterais stricto sensu. Pode-se citar como exemplo o caso da Associação de Nações do Sudeste Asiático (ASEAN), fundada em 1967 e composta por dez Estados: Brunei, Camboja, Indonésia, Laos, Malásia, Myanmar, Filipinas, Cingapura, Tailândia e Vietnã. Apesar de serem vizinhos próximos, a China só reconheceu esse agrupamento de países em 1975, pois considerava a ASEAN um locus de disputa envolvendo questões ideológicas na esteira da Guerra Fria. O caso da ASEAN é emblemático pois mostra com clareza a postura reticente da China quanto ao ambiente internacional, inclusive com o seu próprio entorno geográfico

A segunda fase se inicia a partir de 1981, com uma atitude de maior suporte da China diante das operações. É nesse período que Pequim começa a votar a favor de várias resoluções no Conselho de Segurança e a pagar sua contribuição anual. Em abril de 1990, a China enviou o primeiro contingente de observadores para uma operação da ONU - a UNTSO (United Nations Truce Supervision Organization), no Oriente Médio. Dois fatores explicam essa mudança no comportamento chinês, um doméstico e outro externo: em primeiro lugar, as reformas liberais iniciadas no início dos anos 1970 por Deng Xiaoping; segundo, o ambiente internacional mais favorável.

Na terceira fase, a China envia pela primeira vez uma contribuição de unidades militares. A inflexão comportamental abrupta aconteceu entre 1992 e 1993, com o envio de tropas para a UNTAC (United Nations Transitional Authority in Cambodia), no vizinho Camboja. Foi o único episódio que envolveu uma contribuição desse tipo por parte dos chineses em toda a década. Nesse mesmo período, a China se absteve de autorizar o capítulo que autorizava as non-consensual peace enforcement missions, mantendo-se inativa diante do genocídio em Ruanda e do caos interno na Iugoslávia.

Esse comportamento se altera na quarta etapa da presente análise histórica, quando Pequim começa a demonstrar suporte às missões de peace enforcement e de administrações de transição no Timor-Leste. Nessa fase, a China também dá um salto no perfil das suas contribuições, enviando equipes altamente treinadas na área de logística, engenharia e medicina, todas essenciais para o suporte das missões no terreno - campos de atuação deficitários entre os Estados menos desenvolvidos que costumam contribuir ativamente junto às operações.

Na quinta e última fase, incluída apenas na análise de Fung (2015), a China modifica decisivamente o perfil de seu pessoal enviado, passando a contribuir 
ativamente com tropas de combate. Tal inflexão representa a quebra mais importante em uma perspectiva evolutiva que começa da completa indiferença. Nesse contexto, foram enviadas forças de segurança para a missão da ONU no Mali (MINUSMA - United Nations Multidimensional Integrated Stabilization Mission in Mali), em 2013, e pela primeira vez foi aprovado o envio de um batalhão completo de infantaria, em fins de 2014. O destino foi a UNMISS (United Nations Mission in South Sudan), no Sudão do Sul, que recebeu da China - além dos soldados de capacete azul - drones, mísseis antitanque e veículos de guerra blindados.

O primeiro comunicado oficial que a China estava formalmente considerando mudar seu perfil de contribuição, incluindo os recursos militares de ponta de lança, foi em julho de 2010, quando o ELP (Exército de Libertação Popular) notou que, para enviar tropas de infantaria para o exterior, os tomadores de decisão chineses "levariam em conta nossa política de defesa nacional, que é defensiva por natureza, a resposta da comunidade internacional, bem como a capacidade de nossas tropas". A China enviou forças de segurança abrangentes para o Mali em 2013 e, em 2014, comprometeu um batalhão de tropas de combate no Sudão do Sul, com drones, mísseis antitanques e veículos blindados, sob um claro mandato de proteção civil. (FUNG, 2015, p. 6-7)4

Para efeito auxiliar na compreensão, a contextualização histórica descrita nas últimas linhas está sumarizada no quadro abaixo.

\section{Quadro 2. As cinco fases do envolvimento chinês nas operações de paz}

\begin{tabular}{|c|c|l|}
\hline Fase 1 & $1971-1980$ & Distanciamento e oposição à criação e continuação das operações. \\
\hline Fase 2 & $1981-1990$ & $\begin{array}{l}\text { Atitude de maior suporte, votando a favor de resoluções e pagando a } \\
\text { contribuição anual. Envio do primeiro contingente de observadores. }\end{array}$ \\
\hline Fase 3 & $1992-1998$ & $\begin{array}{l}\text { Envio da primeira contribuição de militares, para o Camboja. Abstenção } \\
\text { quanto às missões de peace enforcement. }\end{array}$ \\
\hline Fase 4 & $1999-2012$ & $\begin{array}{l}\text { Suporte às missões de peace enforcement e de transição no Timor-Leste. } \\
\text { Envio de equipes de apoio altamente capacitadas. }\end{array}$ \\
\hline Fase 5 & 2013-presente & $\begin{array}{l}\text { Contribuições com tropas de combate e primeiro envio de um batalhão } \\
\text { completo de infantaria, para o Sudão do Sul. }\end{array}$ \\
\hline
\end{tabular}

Fonte: Elaboração própria com base em Fravel (1996), He (2007) e Fung (2015).

4 The first official notice that China was formally considering changing its peacekeeping deployment profile, to include tip-of-the-spear military assets was in July 2010, when the PLA noted that in order to deploy infantry troops abroad, Chinese decision-makers would 'take into account our national defense policy, which is defensive in nature, the international community's response, as well as our troop's capability'. China deployed comprehensive security forces to Mali in 2013, and in 2014. China committed a battalion of combat troops to South Sudan, complete with drones, anti-tank missiles, and armored carriers, under a clear civilian protection mandate. 


\section{Análise quantitativa descritiva}

Observando visualmente a evolução da contribuição chinesa para as operações de paz, pode-se ver claramente que há um salto abrupto a partir de 2002. Antes disso, a única descontinuidade no padrão das contribuições aprovadas por Pequim acontece em 1992, devido à missão no Camboja, quando a China salta de um pessoal de 44 para quase 500. Um ano depois, concluído o processo de transição no país vizinho, a contribuição chinesa retorna à casa das dezenas. Tal episódio pode ser interpretado como um indicativo de que a China lança mão do arcabouço institucional proporcionado pela ONU para legitimar sua atuação quando há interesses em jogo - os chineses apoiaram o Camboja durante a guerra civil.

\section{Gráfico 1. Contribuição total e tropas enviadas pela China para as operações de paz}

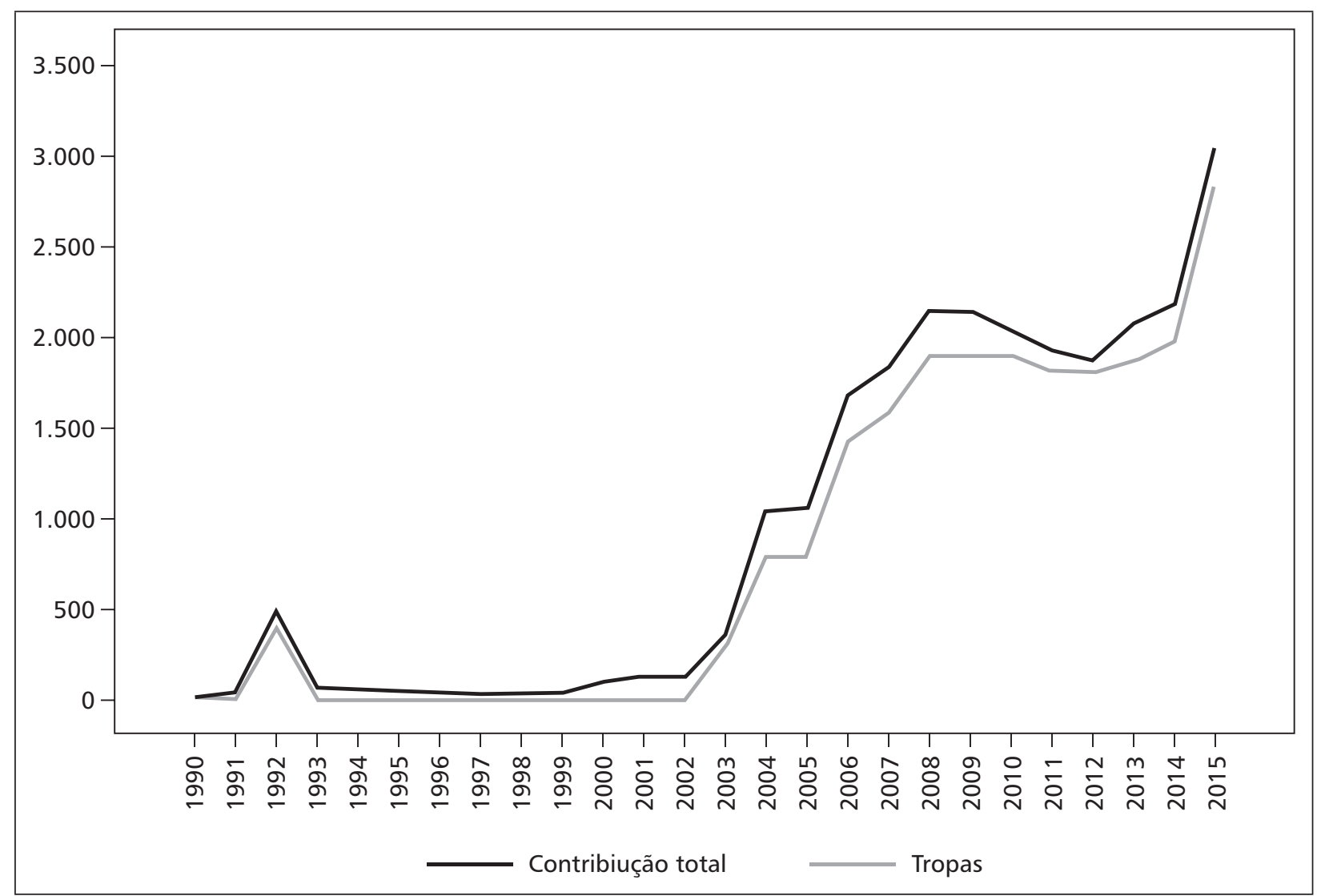

Fonte: Elaboração própria com base em dados da ONU (peacekeeping.un.org)

Adicionalmente, cabe a ressalva de que a quantidade de tropas enviadas pela China (linha cinza) segue o mesmo padrão das contribuições totais (linha preta) ${ }^{5}$,

5 As contribuições podem ser de militares (uniformed personnel) ou de civis (civilian personnel). No primeiro caso, a contribuição pode ser de tropas, polícia ou observadores. No segundo, há os civis locais e os civis internacionais. 
geralmente de observadores e equipes técnicas (médicos, engenheiros etc.). Com exceção do Camboja, a China só volta a enviar tropas significativamente a partir de $2003^{6}$. Nesse ano, autoriza o envio de um quantitativo pessoal de 221 para as tropas da ONU na República Democrática do Congo (MONUC - Mission de l'Organisation des Nations Unies en République démocratique du Congo) e de 68 para as tropas na Libéria (UNMIL - United Nations Mission in Liberia). Apesar de tais eventos representarem de alguma forma uma espécie de marco, os principais pontos de inflexão observados no gráfico 1 - novamente excluindo o caso do Camboja - acontecem a partir do ano seguinte.

De 2003 para 2004, a contribuição de pessoal salta de 358 para 1.036. Nesse mesmo período, a participação da China passa de sete para 12 operações (de um total de 17). O segundo momento onde se observa uma mudança mais ou menos abrupta acontece de 2005 para 2006: a contribuição sai de 1.059 para 1.666. No último momento da série temporal, mais uma inflexão considerável: a contribuição salta de 2.181 em 2014 para 3.045 no ano seguinte. Nesses dois últimos momentos, a quantidade de missões que a China participa não sofre mudanças de impacto.

Especificamente, dois países concentram grande parte das contribuições chinesas na fase final da série: Libéria e Sudão. Os conflitos nesse último acabaram por dar origem ao Sudão do Sul, que atualmente recebe a maior quantidade de tropas chinesas dentre todas as operações para as quais Pequim envia pessoal. A missão no Sudão (UNMIS - United Nations Mission in Sudan) foi aprovada pelo Conselho de Segurança no começo de 2005, ano em que a China enviou para aquele país um pessoal de 35, sendo apenas 8 destinados a tropas. Já no ano seguinte, os chineses aumentaram a contribuição à UNMIS para 469. Pequim manteve a contribuição em torno desse quantitativo, enquanto enviou mais de 500 para a missão na Libéria. Abaixo, as estatísticas descritivas das variáveis em questão.

6 Em 2001, enviou apenas um soldado para a MONUC, na República Democrática do Congo, tendo repetido a mesma quantidade no ano seguinte, quando também mandou um soldado para a UNIKOM (United Nations Iraq-Kuwait Observation Mission), no Iraque-Kuwait. Ressalte-se que não foram militares de combate em nenhum dos casos. 
Tabela 1. Estatísticas descritivas das contribuições totais e das tropas enviadas pela China $^{7}$

\begin{tabular}{|c|c|c|c|c|c|}
\hline \multicolumn{2}{|l|}{$\mathrm{N} 1^{\circ}$} & Mínimo & Máximo & Média & Desvio padrão \\
\hline Tropas & 194 & 0 & 1051 & 109,4 & 189,49 \\
\hline Contribuição & 194 & 1 & 1068 & 126,6 & 196,12 \\
\hline $\mathrm{N}^{\mathrm{o}}$ & 194 & & & & \\
\hline
\end{tabular}

Fonte: Elaboração própria com base em dados da ONU (peacekeeping.un.org).

Os pontos máximos observados nas duas variáveis foram registrados exatamente no último ano da série, na missão no Sudão do Sul (UNMISS). Apesar disso, é de se notar que a média geral da contribuição total e do envio de tropas segue relativamente baixa. $\mathrm{O}$ fato de a China ter permanecido com uma participação discreta nas operações por mais de dez anos certamente tem influência decisiva no resultado da média. Caso permaneça a tendência crescente de contribuições observada recentemente, não restam dúvidas de que a média crescerá - o que deve acontecer mesmo ocorrendo uma estabilização do quantitativo de pessoal enviado.

A concentração de grande parte das operações em solo africano é o gatilho para muitas das análises que atribuem apenas a fatores materiais a explicação do engajamento chinês nas operações de paz. Os dois gráficos abaixo revelam visualmente como a África lidera com folga o recebimento das contribuições da China $^{8}$ - a exceção particular fica por conta do Líbano, $3^{\circ}$ país no ranking das contribuições chinesas. As barras mais escuras indicam a contribuição total, enquanto as mais claras representam somente a quantidade de tropas.

7 O ' $\mathrm{N}$ ' representa o somatório de todas as missões que a China participou ano a ano. As missões que receberam contribuições chinesas em mais de um ano foram contadas mais de uma vez. Sendo assim, o 'N' constitui a quantidade total de observações da análise quantitativa aqui realizada.

8 A literatura nos campos da Ciência Política e das Relações Internacionais sobre as relações entre China e África tem se desenvolvido intensamente ao longo das últimas décadas, cobrindo uma diversidade de temas. Entre os mais abordados pela comunidade acadêmica, podemos citar: o histórico das relações políticas e diplomáticas (MITCHELL; McGIFFERT, 2007; VISENTINI, 2011); a institucionalização da parceria por meio do Fórum de Cooperação China-África (FOCAC) (VADELL et al., 2013; ANSHAN, 2007; MONTENEGRO; ALVES, 2016); a dinâmica econômica das relações, com especial ênfase à demanda chinesa por recursos energéticos e os vultosos investimentos diretos destinados aos países africanos (CARNEIRO LEÃO, 2009; PAUTASSO; OLIVEIRA, 2008; WANG, 2007). 
Gráfico 2. Contribuição da China para as operações de paz por continente

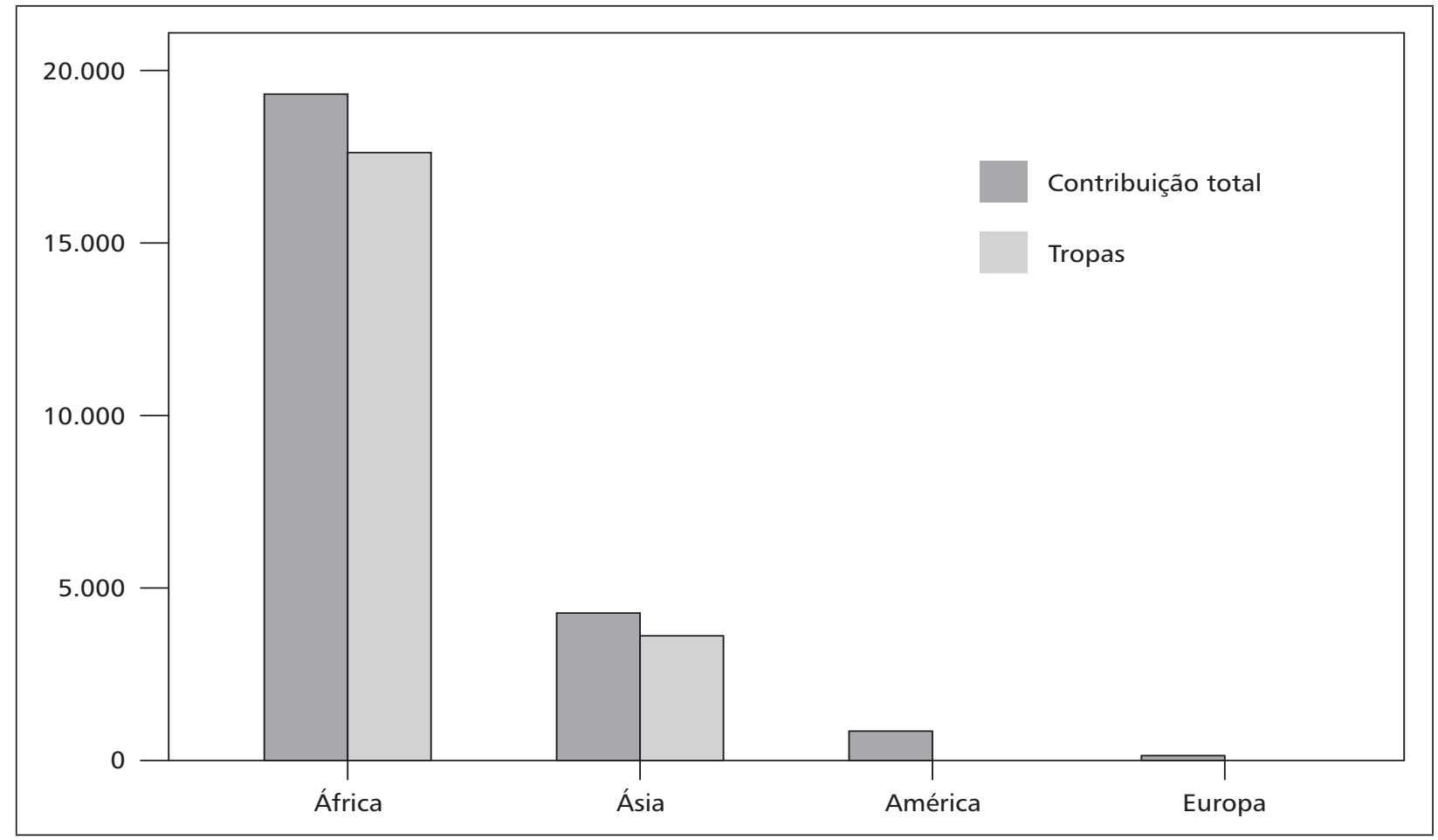

Fonte: Elaboração própria com base em dados da ONU (peacekeeping.un.org).

\section{Gráfico 3. Contribuição da China para as operações de paz por país/região}

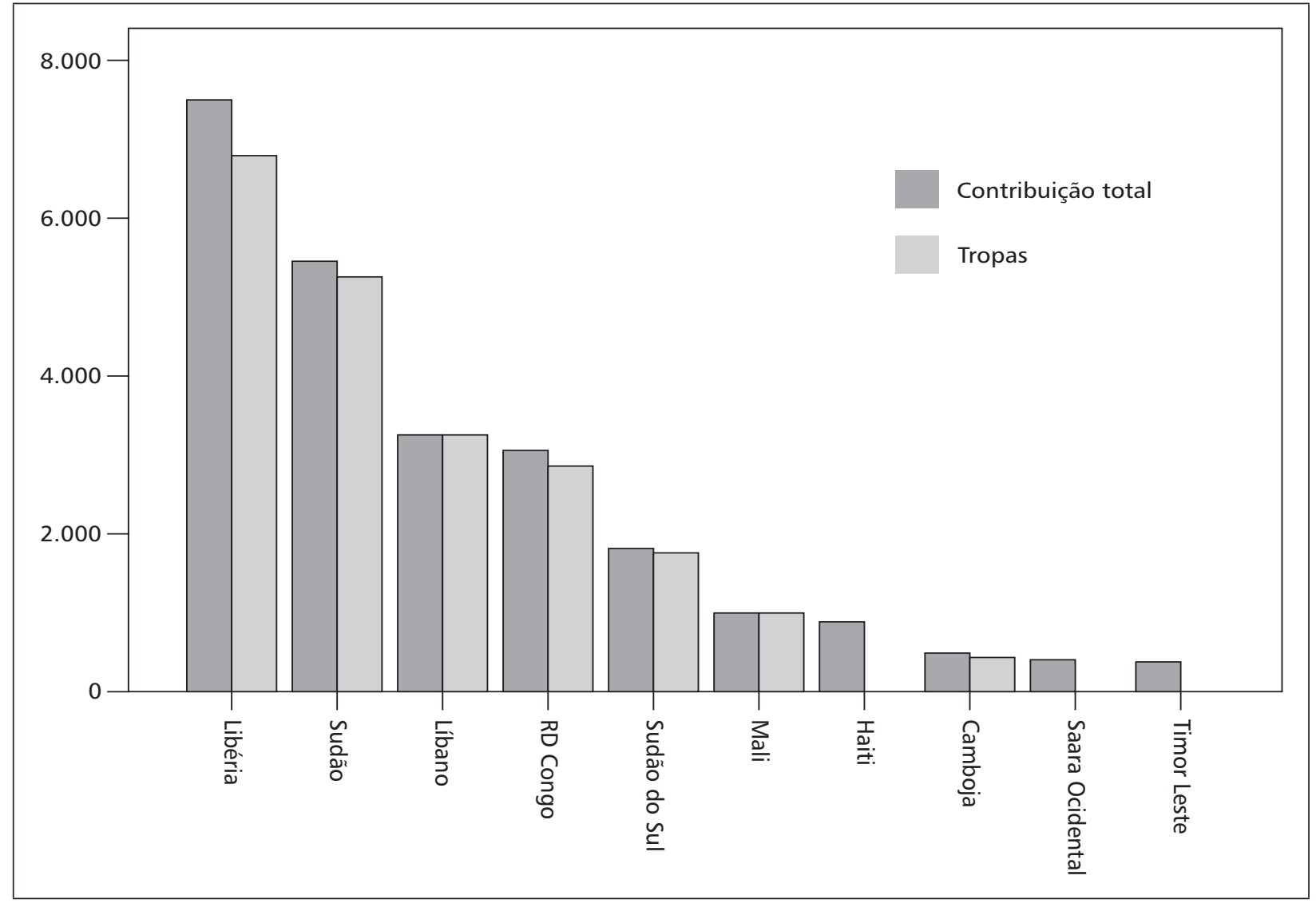

Fonte: Elaboração própria com base em dados da ONU (peacekeeping.un.org). 
A Libéria figura em primeiro lugar como país que mais recebe contribuições chinesas em termos de operações de paz. Essa liderança muito se deve ao fato de a Libéria já ter recebido uma missão da ONU nos anos de 1990 (UNOMIL United Nations Observer Mission in Liberia), além de a missão atual (UNMIL) ter sido estabelecida ainda em 2003. A China contribuiu no primeiro caso e faz o mesmo com a UNMIL desde a criação da mesma. Pequim estabeleceu relações diplomáticas com a Libéria em 1977, tendo rompido anos depois devido ao fato de o País africano ter reconhecido Taiwan. As relações foram restabelecidas em 2003, quando a Libéria rompeu com Taiwan e voltou a reconhecer a China comunista.

Para se ter uma ideia da magnitude do imbróglio envolvendo a Libéria, a China lançou mão do arcabouço institucional da ONU para, de certa forma, barganhar seu reconhecimento diplomático e isolar Taiwan. Durante o regime comandado por Charles Taylor, a Libéria buscou manter relações com as duas Chinas. Taylor renunciou ao cargo em agosto de 2003, a operação de paz da ONU (UNMIL) foi estabelecida em setembro e em outubro os comunistas foram reconhecidos como a China única.

Quando o CSNU (Conselho de Segurança das Nações Unidas) inicialmente concordou em estabelecer uma missão e enviar uma força de estabilização à Libéria após a queda do regime de Charles Taylor, a China apoiou apenas um mandato de três meses para a operação, embora pelo menos seis meses fossem necessários para a mobilização e a força de manutenção da paz. A China então persuadiu a ONU a intervir para garantir que o governo pós-Taylor reconheceria a China. Um mês após a resolução de setembro de 2003 do Conselho de Segurança da ONU (1509) autorizando por 12 meses a força de estabilização na Libéria, China e Libéria restabeleceram relações diplomáticas (em 11 de outubro de 2003). (MEDEIROS, 2009, p. 185)9

No Sudão e no Sudão do Sul, a despeito de não haver um contexto diplomático conturbado no que tange à "One China Policy", a preocupação da China tem cunho econômico e estratégico, haja vista os grandes investimentos realizados em exploração de petróleo naquela região. Na imprensa ocidental, não é difícil encontrar relatos de que a principal motivação chinesa em enviar soldados para

9 When the UNSC initially agreed to establish a mission and send a stabilization force to Liberia after the fall of Charles Taylor's regime, China supported only a three-month mandate for the operation even though at least six months were necessary for the initial mobilization and deployment of the peacekeeping force. China then persuaded the U.N. to intervene to ensure that the post-Taylor government would recognize China. A month after the September 2003 UNSC resolution (1509) authorizing for 12 months the stabilization force in Liberia, China and Liberia reestablished diplomatic relations (on October 11, 2003). 
a missão de paz no Sudão do Sul consiste em proteger seus campos de petróleo e os trabalhadores - chineses em sua imensa maioria - que neles atuam (WALL STREET JOURNAL, 2014).

Na Libéria, comentários nessa linha não existem ou são poucos, mas a China possui investimentos na exploração de minério de ferro, principal recurso natural daquele país. Na seção seguinte, discutimos em profundidade os principais fatores levantados pela literatura para explicar o engajamento chinês nas operações de paz da ONU, que vão de aspectos materiais a ideacionais.

\section{Os determinantes do engajamento: uma síntese da literatura}

A grande maioria da literatura que se propõe a investigar a participação chinesa em operações de paz da ONU lança mão de uma abordagem qualitativa. Dentro dessa perspectiva, muitas análises privilegiam o uso de narrativas históricas, seja para enfatizar a evolução da China como um peacekeeping state, seja para delinear os principais fatores envolvidos na decisão de enviar pessoal às missões. Grosso modo, as variáveis explicativas mais utilizadas pela literatura se identificam com três grandes correntes teóricas das Relações Internacionais: realismo, liberalismo e construtivismo ${ }^{10}$.

Os determinantes de viés realista são bastante utilizados na perspectiva do autointeresse e da maximização de poder, caso em que se encaixam os argumentos que definem a participação chinesa em termos de interesses materiais, geralmente econômicos e estratégicos. Explicações que se identificam com o liberalismo priorizam o papel das normas e instituições. Há ainda as variáveis que dizem respeito exclusivamente à identidade internacional chinesa, uma preocupação observada mais comumente nos debates construtivistas. Alguns trabalhos, cabe notar, desenvolvem um instrumental analítico que percorre mais de uma corrente teórica. Tendo em conta tal hibridismo, o presente artigo busca agrupar as causas levantadas pela literatura em categorias explicativas mais amplas, que busquem suplantar possíveis discordâncias no nível da teoria.

10 No âmbito teórico, tem sido ampla e difusa a aplicação de referenciais estritamente ocidentais, o que tem de certa forma enviesado as conclusões a respeito da política externa chinesa (ZHENG, 2010). A partir do trabalho seminal de Fairbank (1983), muitos pesquisadores começaram a incorporar aspectos do pensamento confucionista para desenvolver um corpus teórico mais adequado ao entendimento do comportamento internacional chinês. Esse debate tem se relevado profícuo não apenas no campo da análise da política externa chinesa, como também na área da teoria das relações internacionais (JOHNSTON, 1995; FENG, 2007; YAN, 2011). 
Apesar de muitas explicações estarem centradas em aspectos materiais, um fator presente em praticamente todos os trabalhos sobre o tema incide sobre a questão da identidade: o fato de a China querer passar a imagem de um "poder responsável” (responsible power). Para Richardson (2011), expressões usadas recorrentemente pelo discurso oficial chinês - como harmonious world, peaceful rise e responsible power ${ }^{11}$ - revelam um espelho de duas faces no que diz respeito ao papel do país nas operações de paz da ONU: por um lado, indica a preferência de como os chineses desejam ser percebidos; por outro, revela as preocupações sobre como os outros observam a China.

Nesse sentido, Pequim tem quatro benefícios ao portar-se como um poder responsável nas discussões sobre seus esforços de peacekeeping: 1) a adaptação do discurso sobre seu papel nas operações de paz, moldando percepções e expectativas sobre a atuação do país nesse regime, além de facilitar a transição para o status de grande potência com o mínimo de ruptura; 2) permite à China ter um esforço retórico de ganhar reconhecimento como uma grande potência legítima, mas nos seus próprios termos, mantendo também o status de "non-Western, non-imperialist developing state"; 3) o termo "poder responsável" habilita a China a renovar suas críticas à ordem existente de acordo com a evolução da percepção que tem da natureza do sistema; 4) por fim, o termo ainda faz com que a China possa se posicionar como um grande poder atípico, enfatizando o desenvolvimento pacífico e a intenção de não desestabilizar a política internacional em função de interesses próprios (RICHARDSON, 2011).

De forma análoga, um relatório do International Crisis Group (2009) também aponta que as operações das Nações Unidas são uma forma relativamente barata para que a China demonstre estar comprometida em apoiar a paz e a segurança internacionais, além de mostrar que o crescimento em termos de poder militar não é inerentemente uma ameaça, reforçando seu desejo de ser vista como um poder responsável. Complementarmente, conceitos como o de "poder responsável” e "ascensão pacífica" ainda revelam uma autoconfiança crescente do governo comunista, baseada nas conquistas alcançadas tanto domesticamente como no âmbito internacional. Tal retórica indica a crença entre as lideranças chinesas de

11 O termo "responsible power" (fuzeren daguo) foi cunhado em 1999 pelo então premier Zhu Rongji e bastante utilizado durante o mandato de Jiang Zemin. Já o "peaceful rise", utilizado em um discurso do influente membro do partido Zheng Bijian, tornou-se uma espécie de política oficial na presidência de Hu Jintao. A utilização do conceito de "mundo harmonioso" ou "sociedade harmoniosa", embora tenha raízes na filosofia ancestral chinesa, também começou com Hu Jintao, mas ganhou força no mandato de Xi Jinping, que frequentemente lança mão dessa retórica. 
que o país pode ser seletivamente ativo e fazer algo que valha a pena (you suo zuo wei) enquanto mantém o "low profile” (HE, 2007; YAN, 2014).

Por meio de uma metodologia qualitativa mista que incluiu entrevistas com elites chinesas e das Nações Unidas, consultas a fontes escritas e observação participante no Departamento de Operações de Paz da ONU, Fung (2015) reconstruiu o caso da missão em Darfur (UNAMID - United Nations Mission in Darfur) para provar que a identidade é uma variável causal chave nas decisões individuais da China sobre cada operação. Para a autora, fatores materiais podem até ser uma condição necessária para o envio de pessoal, mas sozinhos são insuficientes para explicar o cálculo chinês. Assim, há uma inter-relação entre os aspectos materiais e identitários, sendo esses últimos primordiais para se entender a forma como a China se percebe na política internacional, atuando simultaneamente como uma grande potência e um membro do Sul global - daí a maleabilidade do termo “poder responsável”.

Três questões mais amplas vêm desses achados. Primeiro, em termos de assuntos de segurança multilateral, o artigo indica que é importante entender a motivação para as potências emergentes se tornarem provedores de segurança global (...) Segundo, em termos de política externa chinesa, como interpretamos as condições de escopo para quando a identidade pode afetar o posicionamento da China nos fóruns multilaterais? Embora os estudiosos observem há muito tempo que a China é um Estado particularmente preocupado com sua identidade e reconhecimento de status, ainda não conseguimos identificar com precisão a disposição ocasional da China de sacrificar o status e isolar seus grupos de referência nas decisões de política externa no Conselho de Segurança da ONU. (...) Terceiro, entender as implicações dos grupos de referência no comportamento chinês em termos de segurança multilateral fala de forma mais ampla sobre as ações da China em relação à intervenção. (FUNG, 2015, p. 22-24)12

Até mesmo um dos poucos estudos empíricos quantitativos a respeito do assunto chegou à conclusão de que o desejo de se portar como um poder

12 Three broader questions come out of these findings. First, in terms of multilateral security affairs, the article indicates that understanding the motivation for rising powers' to become global security providers is important (...) Second, in terms of Chinese foreign policy, how do we interpret scope conditions for when identity can affect China's positioning at multilateral fora? Though scholars have long noted that China is a state particularly concerned about its identity and recognition of status, we are still unable to accurately pinpoint China's occasional willingness to sacrifice status and stand-alone from its reference groups in foreign policy decisions at the UN Security Council (...) Third, understanding the implications of reference groups on China's multilateral security behavior speaks to China's actions regarding intervention more broadly. 
responsável teve impacto significativo na participação chinesa em missões de paz. No entanto, tal argumento apenas se aplica às operações realizadas antes da década de 2000. Modelos de regressão de mínimos quadrados ordinários (OLS) demonstraram que elementos como a presença de reservas de petróleo, fluxo comercial e a possibilidade de exercer influência diplomática tendem a resultar no envio de forças de paz por parte da China. O mesmo trabalho utilizou uma análise qualitativa de $\mathrm{N}$ médio para mostrar que esses fatores estratégicos não exerciam grande influência antes de 2000, indicando uma rationale diferente por trás do processo decisório chinês, cujas contribuições nesse período eram basicamente de observadores militares (LIN-GREENBERG, 2009) ${ }^{13}$.

Hang (2013) também empreendeu uma tentativa de entender o envolvimento chinês nas missões de paz por meio de análise quantitativa. Aplicando modelos de regressão linear e logística, o autor examinou a influência de variáveis econômicas, territoriais, reputacionais e de segurança no processo decisório chinês em torno das operações. Assim como o trabalho de Lin-Greenberg, os resultados apontaram que países com alto volume comercial com a China tendem a receber um número maior de peacekeepers.

Uma maneira mais pragmática de entender a conexão entre interesses econômicos e o envio de contribuição para operações de paz é reconhecer uma relação positiva entre a quantidade de chineses vivendo e trabalhando no exterior e a preocupação do governo comunista com a segurança dessas pessoas. Dados de 2009 do Ministério do Comércio estimavam que mais de cinco milhões de cidadãos chineses trabalhavam fora do País. Nesse sentido: "Incidentes relatados de trabalhadores chineses ameaçados na Etiópia, Sudão, Somália e outros países levaram a China a desenvolver iniciativas para lidar com a segurança de seus cidadãos no exterior" (RICHARDSON, 2011, p. 292) ${ }^{14}$.

Outro aspecto material mencionado na literatura, adicionalmente aos interesses de ordem comercial e garantia de recursos naturais e energéticos, diz respeito ao próprio desenvolvimento interno chinês per se. O crescimento político, econômico e militar de forma acelerada teve impacto direto na política externa da China, que

13 Cabe ressaltar que os resultados alcançados pela análise quantitativa de Lin-Greenberg (2009) são relativamente limitados devido ao tamanho da amostra. Todavia, apesar da dificuldade em observar significância estatística nesse caso, os modelos de regressão costumam estar corretos ao demonstrarem a direção (positiva ou negativa) dos coeficientes.

14 Reported incidents of Chinese workers under threat in Ethiopia, Sudan, Somalia and elsewhere pushed China to develop initiatives to deal with the safety and security of its nationals abroad. 
se tornou mais "muscular e assertiva” (MASTRO, 2015). Uma diplomacia de viés coercitivo executada por Pequim é vista com clareza na atuação do país na Ásia, principalmente nos litígios envolvendo o Mar do Sul da China, onde o militarismo e as demonstrações de força têm sido as estratégias mais usadas.

A bem da verdade, é fato que o crescimento doméstico impressionante da China ao longo das últimas décadas antecede os investimentos realizados internacionalmente pelo governo comunista. Foram elementos internos que proporcionaram à China a condição de ter recursos disponíveis para aumentar sua participação em questões internacionais, incluindo as operações de paz. Em 2003, por exemplo, o governo investiu US\$ 20 milhões na construção de um centro de treinamento voltado para a capacitação de peacekeepers policiais civis (HE, 2007).

A participação nas operações de paz e a diversificação do tipo de forças enviado também permite à China desenvolver a capacidade operacional do Exército de Libertação Popular (PLA). O envolvimento mais ativo de tropas chinesas acelera a profissionalização das forças armadas, além de ser uma oportunidade de testar as capacidades de projeção de poder do país. Tais fatos revelam uma nova diretriz da diplomacia militar chinesa, que também inclui exercícios conjuntos com países asiáticos, africanos e europeus (notadamente, a Rússia), bem como a observação de grandes exercícios militares ocidentais, caso do Valiant Shield conduzido pelo Comando do Pacífico dos Estados Unidos (MEDEIROS, 2009; HUANG, 2011).

Questões envolvendo o reconhecimento diplomático de Taiwan também constituem um determinante importante no processo decisório da China referente às operações de paz da ONU, como já mencionado no caso da Libéria. Entretanto, esse fator tem sido relativizado pelo governo chinês recentemente, demonstrando uma adaptação quanto ao tema. Tal fenômeno pode ser observado no envio de tropas a países que oficialmente não reconhecem a República Popular, caso da contribuição à MINUSTAH (Mission des Nations Unies pour la Stabilisation en Haïti), no Haiti (INTERNATIONAL CRISIS GROUP, 2009).

De fato, as operações no Haiti, especialmente, não apenas representam o contínuo apoio da China à manutenção da paz da ONU, mas também demonstram que sua abordagem se tornou mais sofisticada do que na década de 1990. O Estado caribenho não reconhece formalmente a República Popular da China, mantendo laços com o governo de Taiwan. No passado, a China resistiu a apoiar as operações da ONU em países que não reconheciam a 
RPC, como exemplificado pelo veto às missões de paz da ONU na Guatemala em 1997 e na Macedônia em 1999 (ambos os estados reconheciam Taiwan) (LANTEIGNE; HIRONO, 2012, p. 3) ${ }^{15}$

Para além dos determinantes identitários e materiais, há ainda uma porção da literatura que estabelece uma explicação focando em aspectos como normas internacionais, socialização e interdependência. Até o fim dos anos de 1990, o governo chinês tinha uma clara postura de não dar suporte a operações de peace enforcement, aquelas realizadas mesmo sem o consenso do país recebedor das tropas. Nesse contexto, o Relatório Brahimi, apresentado em 2000, teve uma importância decisiva para o aumento da participação chinesa nas operações de paz, já que a implementação de novas condutas por parte da ONU coincidiu com as demandas feitas por Pequim no sentido de reformar o arcabouço institucional das missões ${ }^{16}$.

Uma das recomendações assimiladas, e também uma reivindicação antiga da China, foi a restrição do uso da força para a salvaguarda das missões. A análise das votações da China no Conselho de Segurança revela um amplo suporte diplomático vindo de Pequim à nova estrutura das operações, implementada com a adoção do Relatório Brahimi. Essa mudança de comportamento não só pode ser creditada a uma maior aceitação da norma institucional por parte da China, mas também à experiência adquirida por Pequim durante o envolvimento inicial como um peacekeeping state ao longo dos anos de 1990 (STÄHLE, 2008).

Na esteira desses acontecimentos, a norma internacional passou a priorizar mais os direitos humanos do que propriamente a soberania dos Estados, o que coincidiu com uma difusão mais consolidada da norma dos direitos humanos e de intervenção humanitária no interior da China por meio de uma variedade de agentes - principalmente, elites de política externa em Pequim e Xangai e grupos específicos do exército nacional. No caso das elites, entrevistas com dirigentes que as integram demonstraram uma maior parcimônia quanto à intersecção entre

15 In fact, the Haiti operations, especially, not only represent China's continuing support for UN peacekeeping, but also demonstrate that its approach to the activity has become more sophisticated than that in the 1990s. The Caribbean state does not formally recognize the PRC, instead maintaining ties with the government of Taiwan. In the past, China had been resistant to supporting UN operations in states that did not recognize the PRC, as exemplified by the vetoing of UN peace missions in Guatemala in 1997 and Macedonia in 1999 (both states recognized Taiwan).

16 O Relatório Brahimi foi feito a pedido do então Secretário-Geral Kofi Annan e comandado pelo conselheiro Lakhdar Brahimi. O objetivo era rever os insucessos das operações de paz, postas em xeque com o fracasso em Ruanda e na Bósnia, e estabelecer novas diretrizes. 
intervenção e soberania, com uma ligeira precedência do primeiro quanto ao segundo (CHEN, 2009).

Adicionalmente, dois grupos específicos do Exército de Libertação Nacional tiveram relevância decisiva na promoção da norma das intervenções humanitárias dentro do processo decisório do governo comunista. O primeiro tem base no Escritório de Peacekeeping da China, sob o controle do Quartel General em Pequim, estabelecido em 2001 para coordenar e administrar a participação do exército nas operações. O outro grupo serve na missão da China junto às Nações Unidas, em Nova Iorque.

Ao passo de que possa haver dúvidas quanto à ingerência dessas agências no núcleo decisório do governo comunista, a literatura aponta que a aceitação das normas humanitárias pela burocracia estatal chinesa aconteceu em efeito cascata. O desenrolar dos fatos mostra que, sem dúvidas, a China tem adotado um posicionamento mais flexível quanto ao ordenamento internacional sobre direitos humanos: entre os principais tratados na área, Pequim apenas não ratificou o que versa sobre direitos civis e políticos (International Covenant on Civil and Political Rights) (CHEN, 2009).

O processo de socialização internacional por qual passou a China, principalmente a partir da implementação das reformas de abertura nos anos de 1980, também desempenhou papel decisivo para o maior engajamento do País junto às instituições multilaterais. Por meio de uma metodologia que combinou regressão de Cox com event history model, Li (2010) demonstrou que a probabilidade da China ingressar em organizações intergovernamentais cresce segundo três fatores: 1) se a organização tem papel central dentro de uma rede maior de instituições internacionais; 2) se há países asiáticos entre os membros; e 3) quando todos os membros permanentes do Conselho de Segurança fazem parte da organização. Assim, o envolvimento crescente da China nas operações de paz responde a um processo duplo de construção de uma identidade e busca por aprovação do seu status internacional. Esse argumento traz implicações teóricas de interesse.

Os realistas podem argumentar que construir uma identidade social e buscar aprovação social e status ainda contém motivações materiais ulteriores afinal, uma boa imagem internacional pode e trará benefícios materiais. Além disso, a influência social - a capacidade de alterar o comportamento de outros estados - também pode ser considerada uma forma de poder brando, através do qual um país pode cumprir seus interesses. Nesse sentido, torna-se um meio para um fim. No caso da China, por exemplo, uma boa 
imagem internacional pode ser favorável à grande estratégia de se tornar uma grande potência mundial. Esse argumento certamente parece plausível quando se leva em consideração a onda de interesse da China nas últimas duas décadas na construção de status. Mas, mesmo que a influência social traga recompensas materiais, isso não significa que possamos tratá-la como outra forma de argumentação material, porque as recompensas materiais são acumuladas no futuro indefinido, e os benefícios futuros são sempre fortemente descontados quando comparados com os custos atuais (argumento da "sombra do futuro"). Argumentos realistas (...) irão, sem dúvida, prever a deserção na primeira rodada quando os custos da cooperação sobrepuserem os ganhos potenciais. (LI, 2010, p. 372)17

Tal explicação condiz com o argumento construtivista de que os interesses dos Estados não são fixos, mas socialmente construídos. A participação da China nas operações de paz também guarda relação com o mencionado processo de difusão de normas, que tem raízes na gradual socialização do país no ambiente internacional, fazendo-o crer que o envio de contribuições para as missões da ONU é uma prática socialmente aceitável e permissível. A socialização irreversível ainda fez crescer a interdependência da China com as outras potências em termos de segurança, o que levou o então presidente Jiang Zemin a declarar que "tornou-se difícil para qualquer país realizar seus objetivos de segurança por si só. Somente através do fortalecimento da cooperação internacional podemos efetivamente lidar com o desafio de segurança em todo o mundo e realizar a segurança universal e sustentada"18.

No quadro abaixo, tem-se uma visualização resumida das principais variáveis - agrupadas em três categorias explicativas: aspectos materiais, identitários e

17 Realists might argue that building social identity and seeking social approbation and status still contains ulterior material motivations - after all, a good international image can and will bring material benefits. Moreover, social influence - the ability to alter the behavior of other states - might also be regarded as a form of soft power through which a country can fulfill its interests. In this sense, it becomes a means to an end. In the case of China, for instance, a good international image might well be conducive to China's grand strategy of becoming a major world power. This argument certainly seems plausible when taking into account China's surge of interest over the past two decades in status building. But even if social influence does carry material rewards, this does not mean that we can treat it as another form of material argument, because material rewards accrue in the indefinite future, and future benefits are always heavily discounted when compared with current costs (the 'shadow of the future' argument). Realist arguments (...) will undoubtedly predict defection in the first round when the costs of cooperation override the potential gains.

18 Discurso disponível na versão chinesa do People's Daily publicada em 11 de abril de 2002. "It has become difficult for any single country to realize its security objectives by itself alone. Only by strengthening international cooperation can we effectively deal with the security challenge worldwide and realize universal and sustained security" 
relativos a normas e instituições - levantadas como relevantes para se entender o fenômeno do engajamento chinês junto às operações de paz.

Quadro 3. Principais determinantes da participação chinesa em operações de paz

\begin{tabular}{|c|c|}
\hline \multirow{2}{*}{ ASPECTOS MATERIAIS } & $\begin{array}{c}\text { Interesses comerciais e investimento } \\
\text { Recursos energéticos (oil diplomacy) } \\
\text { Capacidade operacional } \\
\text { Isolar Taiwan }\end{array}$ \\
\hline IDENTIDADE & Poder Responsável \\
NORMAS E INSTITUIÇõES & Grande potência / Líder do Sul global \\
& Socialização \\
& Intervenção humanitária (elites de política externa) \\
& Soberania / Intervenção \\
\hline
\end{tabular}

Fonte: Elaboração própria.

\section{Conclusões}

Ante o exposto acima, pode-se notar que a literatura sobre a participação da China em operações de paz da ONU, apesar de relativamente incipiente se comparada a outros aspectos da política externa chinesa, traz uma considerável amplitude de explicações e alguma variação quanto às perspectivas teóricas. É fato que nem todos os trabalhos se propõem a fazer uma discussão sobre teoria das Relações Internacionais, embora a construção do instrumental analítico per se, por meio da seleção das variáveis mais importantes dentro de um modelo explicativo, já constitua uma opção teórica por parte do pesquisador.

Para Fung (2015), a agenda de pesquisa que questiona os determinantes do envolvimento chinês nas peacekeeping operations desencadeou uma espécie de "subliteratura" que engloba quatro categorias de explicação: 1) proteção de interesses chineses no exterior; 2) busca por exposição operacional; 3) garantir benefícios em termos de reputação; e 4) preocupação relativa à identidade. No presente artigo, reformulamos tal categorização por meio de um entendimento que perpassa três constatações. Primeiramente, os itens 1 e 2 podem ser resumidos - ao lado de outros elementos - como "aspectos materiais". Em segundo lugar, reputação e identidade (itens 3 e 4) dizem respeito a basicamente a mesma coisa para serem agrupadas em categorias diferentes. Por fim, há evidências suficientes 
para constatar que questões normativas e institucionais/burocráticas desempenham um papel relevante para serem ignoradas.

A despeito da variedade de determinantes apresentados pela literatura, sejam eles materiais, ideacionais ou relativos a normas e instituições, pelo menos um elemento está presente em grande parte dos trabalhos: a postura de maior assertividade chinesa tem início nos anos de 1980 devido à paulatina implementação das reformas de abertura propostas pouco tempo antes por Deng Xiaoping (PANG, 2005; CABALLERO-ANTHONY, 2008; MATSUDA, 2016). Os interesses materiais para além do território chinês, a necessidade de ser encarada como uma potência responsável e pacífica ou a empatia com as instituições internacionais são elementos precedidos pela abertura iniciada por Xiaoping.

Em termos acadêmicos, uma iniciativa importante que merece menção é o número especial da International Peacekeeping (v. 18, n. 3, june 2011) dedicado exclusivamente ao tema - que depois se transformou no livro China's Evolving Approach to Peacekeeping, editado por Marc Lanteigne e Miwa Hirono. Os dois autores destacam que, mesmo com a evolução dos trabalhos sobre o assunto, ainda há uma questão mais ampla ainda não respondida: de que forma os policymakers do governo comunista enxergam o engajamento nas operações de paz dentro de uma perspectiva mais ampla da política externa chinesa? Nesse contexto, outras questões importantes também são colocadas.

A questão de saber se a China é uma norm-taker ou norm-maker também é altamente relevante para a questão da manutenção da paz. Sua participação na manutenção da paz provavelmente fortalecerá o atual regime internacional de manutenção da paz como resultado da adoção pela China das normas internacionais? Ou, ao contrário, é provável que a China altere as normas de manutenção da paz de uma maneira que se alinhe com sua própria visão de mundo? (LANTEIGNE; HIRONO, 2012, p. 1-2) ${ }^{19}$

Outro desdobramento importante dentro do tema diz respeito especificamente ao envolvimento da China nas operações em solo africano. É fato que a África propriamente constitui uma região onde há muitos países em desenvolvimento, alguns com sérios conflitos internos, e isso por si só já gera uma alta demanda

19 The question of whether China is a norm-taker or norm-maker is also highly relevant to the issue of Chinese peacekeeping. Is its participation in peacekeeping likely to strengthen the current international peacekeeping regime as a result of China's adoption of the international norms of peacekeeping? Or, on the contrary, is China likely to alter the peacekeeping norms in a way that aligns with its own worldview? 
por missões de paz. Ainda assim, a demanda sozinha não determina o envio de peacekeepers. A contribuição do Japão, por exemplo, é majoritariamente destinada a operações na Ásia - a África representa menos da metade. Por outro lado, Hang (2013) aponta que não se pode afirmar que houve um crescimento fora do normal das contribuições chinesas em missões na África. Pelo contrário, o percentual da participação da China no continente tem se mostrado estável.

Os esforços de pesquisa despendidos até aqui deixam claro que uma conjunção de fatores influencia no processo decisório chinês quanto às operações de paz. Apesar disso, ainda é possível afirmar que há uma certa carência por maior rigor metodológico, o que se dá em parte pela falta de dados estatísticos longitudinais sobre a África. Entretanto, há ferramentas apropriadas que podem vencer esta barreira, como as análises de small-n e medium-n. Dessa forma, trabalhos que busquem suprir tal lacuna, bem como aqueles que consigam integrar a maior quantidade possível de fatores explicativos, são bem-vindos.

Para além das dificuldades metodológicas oriundas da escassez de dados, pelo menos outros três desafios emergem para uma futura agenda de pesquisa: 1) a necessidade de utilizar narrativas históricas como ferramenta auxiliar (meio) e não como um fim em si; 2) a busca por inferências causais que tentem descortinar os mecanismos presentes entre as causas levantadas e o resultado ocorrido; 3) a identificação dos múltiplos atores envolvidos no processo decisório sobre o envio de contribuições para as operações de paz.

Com relação ao primeiro desafio, a ampla quantidade de dados disponibilizados pela Organização das Nações Unidas (em contraste com a ausência desse tipo de informação no que diz respeito, por exemplo, às relações comerciais ou aos investimentos chineses mundo afora) e a própria literatura sobre política externa chinesa já trazem conclusões definitivas o suficiente para que as narrativas históricas sirvam apenas como elemento contextual.

Quanto ao segundo: a essa altura parece claro quais potenciais causas explicam o envolvimento da China em operações de paz, ainda que uma parte significativa da literatura aponte que não é possível generalizar, já que a China enviaria suas contribuições com base em uma análise caso a caso (HANG, 2013; LIN-GREENBERG, 2009). O mesmo argumento é apresentado por Huang (2017) em relatório publicado pelo "Providing for Peacekeeping", projeto independente levado adiante por várias instituições de pesquisa. O que se faz urgente, por ora, é entender de que forma essas causas operam. 
Por fim, quanto ao último desafio, resta suficiente a colocação trazida pelo relatório do International Crisis Group (2009, p. 15): "A caracterização do governo em Pequim como uma entidade unificada e coordenada, uma 'China, Inc', não descreve com precisão o processo de formulação de políticas ou reconhece a natureza em rápida mutação da política externa da China." ${ }^{20}$. Sendo assim, há ainda um longo esforço de pesquisa a ser empreendido pela comunidade interessada em descortinar as nuances do processo decisório chinês em torno das missões de paz.

\section{Referências}

ANSHAN, Li. China and Africa: policy and challenges. China Security, v. 3, n. 3 p. 69-93, 2007.

CABALLERO-ANTHONY, Mely. Rethinking Peace Operations in East Asia: Problems and Prospects. In: DANIEL, Donald C. F.; TAFT, Patricia; WIHARTA, Sharon, eds. Peace Operations: Trends, Progress, and Prospects. Washington: Georgetown University Press, 2008.

CARNEIRO LEÃO, Bruno Guerra. As relações econômicas EUA-China no início do século XXI: análise à luz das dinâmicas concorrentes da geopolítica e da globalização. Tese (Doutorado em Relações Internacionais) - Instituto de Relações Internacionais, Universidade de Brasília, Brasília, 2009.

CHEN, Jing. Explaining the Change in China's Attitude toward UN Peacekeeping: a norm change perspective. Journal of Contemporary China, v. 18, n. 58, p. 157-173, 2009.

CRI Online (Rádio Internacional da China). China organiza primeiro curso de capacitação para missão da paz da ONU. 2016. Disponível em: < http://portuguese.cri. cn/1721/2016/06/07/1s217035.htm > . Acesso em: 30 abr. 2018.

DIÁRIO DO POVO ONLINE. China: Segundo maior financiador para operações de manutenção de paz da ONU. 2016. Disponível em: < http://portuguese.people.com. cn/n3/2016/0530/c309806-9065372.html > . Acesso em: 30 abr. 2018.

FAIRBANK, John King. The United States and China. Massachusetts: Harvard University Press, 1983.

FENG, Huiyun. Chinese Strategic Culture and Foreign Policy Decision-Making: Confucianism, Leadership and War. United Kingdom: Routledge, 2007.

20 The characterization of the government in Beijing as a unified and coordinated entity, a 'China, Inc', does not accurately describe the policymaking process or recognize the rapidly changing nature of China's foreign policy. 
FRAVEL, M. Taylor. China’s Attitude toward U.N. Peacekeeping Operations since 1989. Asian Survey, v. 36, n. 11, p. 1102-1121, 1996.

FUNG, Courtney J. What explains China's deployment to UN peacekeeping operations? International Relations of the Asia-Pacific, lcv020, 1-33, 2015.

HANG, Zhou. Dragon under the Blue Helmet: a quantitative analysis of China's motivation for participation in UN peacekeeping operations. African East-Asian Affairs, Issue 3, Sep. 2013.

HE, Yin. China's Changing Policy on UN Peacekeeping Operations. Institute for Security and Development Policy: Asia Paper, 2007.

HUANG, Chin-Hao. Contributor Profile: The People's Republic of China. Providing for Peacekeeping, 2017. Disponível em: < http://www.providingforpeacekeeping.org/ wp-content/uploads/2017/05/China-Chin-Hao-27Apr2017_FINAL.pdf > . Acesso em: 30 abr. 2018.

HUANG, Chin-Hao. Principles and Praxis of China's Peacekeeping. International Peacekeeping, v. 18, n.3, p. 257-270, 2011.

INTERNATIONAL CRISIS GROUP. China's Growing Role in UN Peacekeeping. Asia Report $N^{\circ} 166,2009$.

JOHNSTON, Alastair Iain. Cultural Realism: Strategic Culture and Grand Strategy in Chinese History. Princeton: Princeton University Press, 1995.

LANTEIGNE, Mark; HIRONO, Miwa. China's Evolving Approach to Peacekeeping. London: Routledge, 2012.

LI, Xiaojun. Social Rewards and Socialization Effects: An Alternative Explanation for the Motivation Behind China's Participation in International Institutions. The Chinese Journal of International Politics, v. 3, p. 347-377, 2010.

LIN-GREENBERG, Erik. Blue-Helmeted Dragons: Explaining China's Participation in United Nations Peace Operations. Dissertação de Mestrado em Ciência Política Massachusetts Institute of Technology, Estados Unidos, 2009.

MASTRO, Oriana Skylar. Why Chinese Assertiveness is Here to Stay. The Washington Quarterly, 37:4, p. 151-170, 2015.

MATSUDA, Yasuhiro. China's UN Peacekeeping Operations Policy: Analysis of the Factors behind the Policy Shift toward Active Engagement. International Circumstances in the Asia-Pacific Series (China), Japan Digital Library, p. 50-68, 2016.

MEDEIROS, Evan S. China's International Behavior: Activism, Opportunism, and Diversification. Santa Monica: RAND, 2009.

MITCHELL, Derek; McGIFFERT, Carola. Expanding the "Strategic Periphery": a history of Chinas's interaction with developing world. In: EISENMAN, J.; HEGINBOTHAM, E.;D. MITCHELL, D. (Ed.). China and the developing world: Beijing's strategy for the twenty-first century. New York: M.E. Sharpe, 2007. 
MONTENEGRO, Renan Holanda; ALVES, João Ricardo Cumarú Silva. China e África além da economia: qual o impacto do FOCAC no âmbito multilateral (1971-2014)? Conjuntura Internacional, v. 13, n. 3, p. 153-162, 2016.

NEW YORK TIMES. China Surprises U.N. with \$100 Million and Thousands of Troops for Peacekeeping. 2015. Disponível em: < https://cn.nytimes.com/china/20150929/ c29xitroops/en-us/ > . Acesso em: 30 abr. 2018.

PANG, Zhongying. China's changing attitude to UN peacekeeping. International Peacekeeping, v. 12, n.1, p. 87-104, 2007.

PAUTASSO, Diego; OLIVEIRA, Lucas Kerr de. A segurança energética da China e as reações dos EUA. Contexto Internacional, v. 30, n. 2, p. 373-374. Dezembro, 2008.

RICHARDSON, Courtney J. A Responsible Power? China and the UN Peacekeeping Regime. International Peacekeeping, v. 18, n.3, p. 286-297, 2011.

SHAMBAUGH, David. China Goes Global: The Partial Power. New York: Oxford University Press, 2013.

STAHLE, Stefan. China's shifting attitude towards United Nations Peacekeeping Operations. The China Quarterly, 195, p. 631-655, 2008.

VADELL, Javier Alberto; LOPES, Bárbara Ferreira; NASCIMENTO, Daniele Cardoso do. FOCAC: estratégia econômica e política de cooperação Sul-Sul Sino-Africana. Carta Internacional, v. 8, n. 2, jul-dez. p. 81-99. 2013.

VISENTINI, Paulo Fagundes. As Relações Diplomáticas da Ásia: articulações regionais e afirmação mundial (uma perspectiva brasileira). Belo Horizonte: Fino Traço, 2011.

WALL STREET JOURNAL. China Deploys Troops in South Sudan to Defend Oil Fields, Workers. 2014. Disponível em: < https://www.wsj.com/articles/china-deploys-troopsin-south-sudan-to-defend-oil-fields-workers-1410275041 > . Acesso em: 30 abr. 2018.

WANG, Jian-Ye. What Drives China's Growing Role in Africa? Working Paper 07/211, International Monetary Fund, Washington, DC. 2007.

YAN, Xuetong. Ancient Chinese Thought, Modern Chinese Power. Princeton: Princeton Univeristy Press, 2011.

YAN, Xuetong. From Keeping a Low Profile to Striving for Achievement. The Chinese Journal of International Politics, v. 7, n. 2, p. 153-184, 2014.

ZHENG, Yongnian (ed). China and International Relations: The Chinese View and the Contribution of Wang Gungwu. New York: Routledge, 2010. 